\title{
Development of A Multiparameter Algorithm for Establishing the Economic Efficiency of Research
}

\author{
Evgeny Bardulin, Lyudmila Zubova, Anna Yakovleva, Olga Zinisha, Lyudmila Piterskaya
}

\begin{abstract}
This article presents the results of the development of a universal multi-parameter algorithm, which consists in applying the research of the level of resistance to financial and economic risks, taking into account the stage of the life cycle of the production process and the level of production stability and technological risks. The relationship between the levels of risk tolerance of subjects from the stage of the life cycle of the production process is revealed and studied. An algorithm for taking preventive measures is proposed.
\end{abstract}

Keywords: algorithm, technological parameters, systematization of data, optimization.

\section{INTRODUCTION}

Risk is a complex phenomenon with many inconsistent, and sometimes opposite, real reasons [1]. In the study of certain tasks, an important factor is the risk management process using a quantitative method for analyzing the risk situation. This analysis involves the numerical determination of both individual risks and the risk as a whole.

Modern economic and mathematical methods are a very effective tool for analysts. Like any developed economic and mathematical theory, it consists of two parts, the first of which is a set of mathematical models, and the second, respectively, is a set of numerical methods.

Therefore, at the moment there is such a problem in the developed complex of analysis and selection of methods for managing and efficient modeling of economic risk, which as such does not exist in the Russian Federation, in which there is no clear justification for the inextricable relationship of

Revised Manuscript Received on December 30, 2019.

* Correspondence Author

Evgeny Bardulin*, Department of Management and Economics, Saint-Petersburg University of State Fire Service of EMERCOM of Russia, Saint-Petersburg, Russia. Email: bardulin@mail.ru

Lyudmila Zubova, Department of Economics and Law, Saint-Petersburg University of State Fire Service of EMERCOM of Russia, Saint-Petersburg, Russia. Email: bardulin@mail.ru

Anna Yakovleva, Department of Management and Economics, Saint-Petersburg University of State Fire Service of EMERCOM of Russia, Saint-Petersburg, Russia. Email: bardulin@mail.ru

Olga Zinisha, Department of monetary circulation and credit, Kuban State Agrarian University, Krasnodar, Russia. Email: zinisha@mail.ru

Lyudmila Piterskaya, Department of monetary circulation and credit, Kuban State Agrarian University, Krasnodar, Russia. Email: zinisha@mail.ru

(C) The Authors. Published by Blue Eyes Intelligence Engineering and Sciences Publication (BEIESP). This is an open access article under the CC BY-NC-ND license (http://creativecommons.org/licenses/by-nc-nd/4.0/) economic risk and business efficiency in trade, there is no clear structuring in that risk minimization leads to maximizing the efficiency of entrepreneurship, maximizing profits, and then correspondingly increasing the budget a. Hence, entrepreneurs have the need for a competent ability to take risks, but at the same time reduce the uncertainty of the situation, make all kinds of maneuvers with resources, adjust the decisions that are already being implemented, and see and derive economic benefits under any circumstances.

The point of view of I. Balabanov, who in turn believes that risk management should be integrated into the corporate process, should have its own strategy, tactics, and operational implementation, is also fair, since it is important not only to carry out risk management, but also periodically review measures and means such a management. I. Balabanov notes that the high efficiency of spending resources when implementing a risk management program can be ensured only within the framework of a systematic approach. [4]

We completely agree with the data of a systematic approach, since such an approach is one of the common ones and consists in a systematic analysis. In entrepreneurial activities in the conditions of economic risk, for an effective decision making it is necessary to consider a certain number of emerging factors that affect the final consequences of the decision: to evaluate factors comprehensively, as we believe, is inefficient and inappropriate. It is necessary to systematize all the available analysis details, identify the most and least important aspects, only then analyze them, and make an informed decision. When making a decision, it is necessary to identify the main problem.

Risk management becomes relevant after the discovery of a risk problem. In this case, the results of risk analysis and modeling should be used. In general, in relation to risk, as a likely failure, the following control actions are possible: prevention, reduction, compensation of damage, absorption. Prevention (elimination) is called the exclusion of the source of risk as a result of the targeted actions of the subject of risk. In risk prevention, two approaches are distinguished: wide and narrow. A narrow approach is to prevent risk through specific activities carried out at the expense of insurance amounts and at the initiative of the insurer. A broad approach is implemented outside insurance. Risk reduction (control) is the reduction in the probability of a risk source being realized as a result of the action of risk subjects. Risk reduction can be carried out by various methods, including through the use of methods such as diversification, securitization, limitation. [4]. 


\section{Development of A Multiparameter Algorithm for Establishing the Economic Efficiency of Research}

\section{MATERIALS AND METHODS}

Risks are classified by subjects, types and manifestations.

A risk subject is a legal or natural person who is consciously in a risk situation. Usually there are three subjects of entrepreneurial risk:

1) manufacturing enterprises;

2) individuals (individuals, recipients of income);

3) other entities (organizations of the non-productive sphere of activity, including government bodies).

A type of entrepreneurial risk is a grouping of situations that are close in terms of risk awareness and behavior in risk situations. In the modern economic literature, there are significant disagreements on the number of types of risk.

Some classifications provide up to ten to thirteen different types of entrepreneurial risks. With all the variety of approaches to risk classification, several main types can be distinguished:

- production (net);

- investment and innovative;

- financial;

- commodity;

- complex;

- banking.

The latter type of risks is singled out in a separate position due to the importance and specificity of its individual manifestations, however, it is sometimes investigated among financial risks. We believe that under the conditions of economic risk, the subject behaves as follows: for starters, the level of risk is determined: low, medium or high, potential losses or potential profits are assumed, all information received and available is analyzed and a considered, balanced decision is made, as a result of which consequences in the form of a positive or negative outcome.

And in order to have a lower risk level, it is necessary to conduct a more systematic analysis: qualitative and quantitative.

Risk analysis is divided into two mutually complementary types: qualitative, the main task of which is to identify risk factors and circumstances leading to risk situations, and quantitative, which allows calculating the sizes of individual risks and the risk of the project as a whole. [9]

I. Lukasevich believes that modeling a risky situation is a series of numerical experiments designed to obtain empirical estimates of the degree of influence of various factors (initial values) on some results (indicators) that depend on them. I. Lukasevich breaks up the simulation experiment into the following stages:

1. Setting the relationship between the source and output indicators in the form of a mathematical equation or inequality.

2. Setting the laws of probability distribution for the key parameters of the model.

3. Carrying out computer simulation values of the key parameters of the model.

4. Calculation of the main characteristics of the distributions of the initial and output indicators.

5. Analysis of the results and decision making.

The results of a simulation experiment can be supplemented by statistical analysis, as well as used to build predictive models and scenarios. [6]

Thus, we conclude that risks can be modeled in different ways, which we see from various information sources, but the essence, as we consider it alone, is this: first of all, determining the level of risk, analyzing everything related to awareness, weighing the possibility of prevailing loss or profit, and only then the adoption of repeatedly considered management decisions, which results in a positive or negative outcome. Whether it is a positive outcome or a negative one, the result should be recorded for the company's own statistics. Contrary to popular belief, recently risk has been most often understood in several different aspects: risk as opportunity, risk as danger or threat, risk as uncertainty.

\section{RESULT AND DISCUSSION}

Risk as an opportunity is based on the concept of the relationship between risk and profitability. The higher the risk, the higher the potential income, but also the higher the probable losses. In this sense, risk management means using the technique of maximizing income while limiting or minimizing losses.

Risk as a danger or threat is the most commonly used concept. In the framework of this approach, negative events are considered, such as financial losses, fraud, theft, reputation threat, damage or bankruptcy, participation in lawsuits, etc. From the point of view of this concept, risk management means the technique of reducing the likelihood of undesirable events or the complete collapse of an organization using a number of measures that require a reasonable cost.

The third point of view is the most academic. In its framework, risk is considered as uncertainty. She appeals to such a theoretical concept as the probabilistic distribution of possible outcomes (positive and negative). From this point of view, risk management has as its subject the reduction of the variance between expected outcomes and actual results.

Based on the proposed definition of risk, approach and indicators for assessing risks, results and the effectiveness of their consequences, we propose two reciprocal indicators that allow us to reflect the level of risks and risk tolerance of the business entity, respectively. The first indicator, the level of risk or risk intensity (Ur), reflects in value form the total value of the risk price (RR) and the costs of its consequences (IR) per unit cost unit of equity (IC) and can be expressed by the following formalization:

$$
\text { Risk level }=\frac{\text { Risk cost }+ \text { Cost Effects of Risk }}{\text { Own funds }}
$$

or formalization

$$
\mathrm{Y}_{\mathrm{p}}=\frac{\mathrm{CR}+\mathrm{I}_{\mathrm{p}}}{\mathrm{CK}}
$$

The second indicator of risk tolerance $\left(\mathrm{R}_{\mathrm{ust}}\right)$ allows you to express risk tolerance. Its economic content consists in the reflection of the covering by own means of an economic entity in terms of value expressed as the aggregate of the price of risk $(\mathrm{CR})$ and the costs of its consequences $\left(\mathrm{I}_{\mathrm{p}}\right)$.

ublished By: 
The risk tolerance indicator can be expressed as follows

$$
\mathrm{R}_{\text {ust }}=\frac{\mathrm{CK}}{\mathrm{CR}+\mathrm{I}_{\mathrm{p}}}
$$

Thus, the indicators of risk tolerance and the level of risk of an economic entity are interdependent and are inversely related to each other.

$$
\mathrm{Y}_{\mathrm{p}}=\frac{1}{\mathrm{R}_{\text {ust }}}
$$

respectively in expanded form

$$
\frac{\mathrm{CR}+\mathrm{I}_{\mathrm{p}}}{\mathrm{CK}}=\frac{\mathrm{CK}}{\mathrm{CR}+\mathrm{I}_{\mathrm{p}}}
$$

In economic theory, a number of indicators have already been built on the basis of this approach. So, the indicator of financial autonomy or financial independence (such indicators are often called financial ratios in scientific sources) measures the amount of equity and borrowed capital of an economic entity and is defined as

$$
\text { Autonomy indicator }=\frac{\text { Equity }}{\text { Borrowed capital }}
$$

characterizes the degree of freedom, the independence of the organization from external loans - the lower its value, the more loans an entity has, and therefore the higher the risk of insolvency and the potential occurrence of a monetary deficit (bankruptcy). It is easy to see that the proposed indicator of risk tolerance (2) and the well-known indicator of financial autonomy, each in its content, carry signs of risk assessment. In this sense, the risk tolerance indicator acts as a general indicator with respect to the indicator of financial independence, since it allows one to evaluate risk tolerance theoretically and practically for any type of activity. In fact, if in the indicator of risk tolerance the denominator of the aggregate price of risk and the costs of its consequences is replaced by borrowed capital, then we obtain the indicator of financial autonomy as a private indicator characterizing financial stability, a more general indicator of risk tolerance.

The results of practical application in the form of calculations performed according to these formulas are

\begin{tabular}{|c|c|c|c|c|c|c|}
\hline № & Indicators & Expert 1 & Expert 2 & Expert 3 & Expert 4 & Expert 5 \\
\hline 1. & $\begin{array}{c}\mathrm{P}_{\mathrm{f}}-\text { (forecast) profit of the } \\
\text { consequences of the } \\
\text { implementation of the decision }\end{array}$ & 2050000 & 2265000 & 1825000 & 815000 & 1615000 \\
\hline 2. & $\mathrm{~S}_{\mathrm{r}}-$ sales revenue & 3000000 & 3200000 & 2900000 & 1900000 & 3100000 \\
\hline 3. & $\begin{array}{l}\text { CR - costs incurred by the entity } \\
\text { in making a risk decision }\end{array}$ & 1000000 & 1100000 & 1100000 & 1050000 & 1500000 \\
\hline 4. & $\begin{array}{c}\mathrm{IN}_{\mathrm{ot}}- \\
\begin{array}{c}\text { other income related to } \\
\text { risk }\end{array} \\
\end{array}$ & 100000 & 200000 & 50000 & 35000 & 25000 \\
\hline 5. & $\begin{array}{c}\mathrm{E}_{\mathrm{ot}}-\text { other expenses related to } \\
\text { risk }\end{array}$ & 50000 & 35000 & 25000 & 70000 & 10000 \\
\hline 6. & A - admission / liquid assets & 4500000 & 4500000 & 4500000 & 4500000 & 4500000 \\
\hline 7. & $\mathrm{E}$ - equity & 10000000 & 10000000 & 10000000 & 10000000 & 10000000 \\
\hline 8. & $\mathrm{R}_{\mathrm{l}}-$ risk level & 0,230 & 0,250 & 0,250 & 0,248 & 0,335 \\
\hline 9. & $\mathrm{R}_{\max }-$ maximum risk tolerance & 9,52 & 8,81 & 8,88 & 8,93 & 6,58 \\
\hline
\end{tabular}
presented in table 1.

As you can see, the indicator of financial autonomy

Table - I: Assessing the maximum possible risk tolerance of an economic entity with five expert alternatives

Thus, the level of maximum possible risk tolerance of the fifth expert is 6.58, and the first 9.52. This is due to lower costs for the implementation of the decision, because the equity of the subject allows you to take this risk. The price of risk directly affects the cost of risk and, accordingly, the level of risk for a given organization (system).

The risk levels of alternatives of the first, second and fourth experts reach values of 0.23 and 0.25 , which refers to low risks and are recommended for implementing the solution. The fifth expert's alternative is evaluated as an average risk level of 0.34 and requires a probability of suppression of 0.82 . Risks of the fifth and ninth levels require approaches to minimize risks, "embed" the risk of insurance costs in the aggregate cost, which in turn will reduce the risk itself due to narrowing the scope of uncertainty.

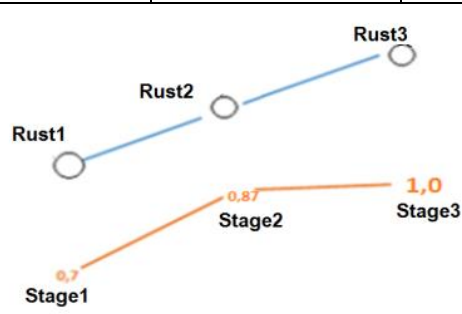

- 0 - R\&D Life Cycle on TTT $\quad-$ risk tolerance level

Fig. 2. Interdependence of dynamics of production and technological risk tolerance of the enterprises of performers from dynamics of financial and economic risk tolerance at certain stages of R\&D 
A universal approach is proposed, consisting in the application of assessing the level of financial and economic risk tolerance, taking into account the stage of the life cycle of the production process and the level of production and technological risk tolerance; to identify the relationship between the levels of risk tolerance of subjects from the stage of the life cycle of the production process. Consideration of this pattern will allow to take preventive measures in advance. The result obtained is universal both for management, for marketing, and for the economy of business entities as a whole.

Specifically, at the stages of development and birth of the production process, the level of risk is high, and the risk tolerance of the defense industry enterprise is low; at the stage of development of production, when TTT is achieved, the risk tolerance increases; at the maturity stage of the production process, risk tolerance reaches a maximum level.

The prospects of this study are the development of a comprehensive methodological support for assessing the risk tolerance of enterprises of performers, which allows assessing the level of risk tolerance in the course of development work while achieving tactical and technical requirements taking into account technical and economic requirements (TET) taking into account the evaluation criteria and threshold values of these indicators.

\section{CONCLUSION}

A new approach to the management of the $R \& D$ process is proposed, the essence of which is: when determining the specified levels of risk tolerance of the executor's enterprise, it will be possible to monitor deviations and determine risks and the results of their consequences that have influenced the actual change in the state of risk tolerance, as well as to monitor the interdependence of the dynamics of risk tolerance of enterprises from the dynamics of the life cycle of OCD for a specific analyzed period.

The prospects of this study are the development of a comprehensive methodological support for assessing the risk tolerance of enterprises of performers, which allows assessing the level of risk tolerance in the course of development work while achieving tactical and technical requirements taking into account technical and economic requirements (TET) taking into account the evaluation criteria and threshold values of these indicators.

Based on the proposed definition of risk, approach and indicators for assessing risks, results and the effectiveness of their consequences, we propose two reciprocal indicators that allow us to reflect the level of risks and risk tolerance of the business entity, respectively.

\section{REFERENCES}

1. S. F. Vikulov, V. I. Babenkov, Military-economic security of the material and technical support system of the Armed Forces. Bulletin of the Military Academy of Logistics Army General A.V. Khrulev. 2016, 3(7), pp. 117-120.

2. A. V. Toporov, V. I. Babenkov, Assessment of threats to military-economic security of material and technical support of troops (forces). Scientific Bulletin of the Volsky Military Institute of Material Support: Military Scientific Journal. 2018, 2(46), pp. 5-11.

3. V. I.Babenkov, Actual problems of economic security of the Russian Federation. Scientific Herald of the Volsky Military Institute of Material Support: Military Scientific Journal. 2017, 3(43), pp. 106-109.
4. V. I. Babenkov, R. R. Bikmetov, A. N. Ivanov, Ensuring the economic security of the material and technical support system of the Ministry of Emergencies of Russia. In collection: Security service in Russia: experience, problems, prospects. ensuring integrated life safety of the population. Materials of the IX All-Russian Scientific and Practical Conference. SPb. SPbUGPS EMERCOM of Russia, 2017, pp. 342-345.

5. E. N. Chizhikov, E. N. Bardulin, V. I. Babenkov, Analysis of economic security threats in emergency situations. Bulletin of the Russian Academy of Missile and Artillery Sciences. 2017, 2(97), pp. 31-37.

6. E. N. Chizhikov, E. N. Bardulin, A. A. Mazhazhikhov, The mechanism for ensuring the economic security of the energy complex in emergency situations. Scientific Herald of the Volsky Military Institute of Material Support: Military Scientific Journal. 2018, 4(48), pp. 179-184.

7. M. N. Kozin, A. E. Erin, Risk assessments for the implementation of creation programs about 2018, 5, pp. 945-949.

8. M. N. Kozin, V. Yu. Malyankin, Proactive risk management of logistics in an organization based on the development of a strategic network sustainability mechanism. Economics and Entrepreneurship. 2018, 9(98), pp. 681-685.

\section{AUTHORS PROFILE}

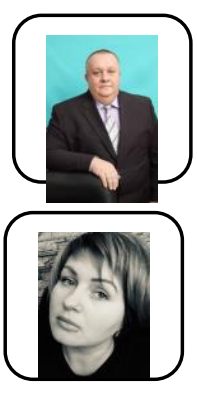

Evgeny Bardulin, Doctor of Economic Sciences, Professor. Scientific interests: economic security, logistical (material and technical) support.

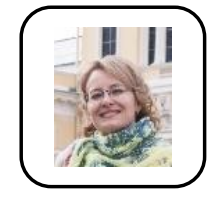

Anna Yakovleva, Doctor of Economic Sciences, Associated Professor. Scientific interests: information security, digital economy, unemployment, unemployment insurance, social insurance, taxation, labor market, intellectual property.

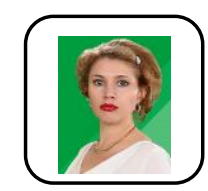

Olga Zinisha, Candidate of Economic Science, Associate Professor. Scientific interests: digital economy, taxation, labor market, intellectual property

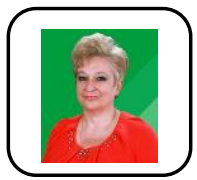

Lyudmila Piterskaya, Doctor of Economic Sciences, Professor. Scientific interests: digital economy, taxation, labor market, intellectual property 